\section{Reply to Lancaster}

European Journal of Human Genetics (2010) 18, 1186-1187; doi:10.1038/ejhg.2010.89; published online 23 June 2010

In January 2010, we published in this journal a report ${ }^{1}$ on the frequency distribution of the $\mathrm{Y}$ chromosome haplogroup Ribla (R-V88) in Africa, where it can be found at frequencies as high as about $90 \%$. This haplogroup (or its ancestor) most likely traces its origins back to Eurasia, but is presently found very rarely outside Africa.

In our original publication, ${ }^{1}$ we described two important patterns in the genotyping data. The first observation was that the highest frequencies of the Rlbla haplogroup were found among Afro-Asiatic-speaking populations from the Central Sahel, with Chadic mostly contributing to this pattern. We have now extended our analysis to a further 258 unrelated male subjects from northern Cameroon (Table 1). As can be seen from Table 1, the extended data fully confirm the pattern originally observed.

The second observation was regarding a genetic contiguity between the Chadic-speaking peoples from the Central Sahel and several other Afro-Asiatic-speaking groups from North Africa, including
Ouarzazate Berbers from Morocco, Mozabite Berbers from Algeria, Siwa Berbers and several Semitic groups from Egypt, and, possibly, different groups from Algeria, ${ }^{2}$ Tunisia $^{3}$ and Egypt, ${ }^{3,4}$ with Rlbla frequencies ranging from 1 to $3 \%$ in Algeria to about $4 \%$ in Tunisia, to $26.9 \%$ in the Siwa. We interpreted these data by suggesting that they are more compatible with Ehret's hypothesis, which proposes that Chadic peoples arrived from the North through the Sahara (the 'transSaharan' hypothesis), ${ }^{5}$ rather than with Blench's theory, which states that Chadic-speaking pastoralists reached the Chad Basin through the Sahel from an eastern Sudanic Cushitic-Chadic motherland (the 'inter-Saharan' hypothesis). ${ }^{6}$

Considering the mitochondrial DNA, the populations from the Chad Basin also show some genetic peculiarities when compared with other populations living south of the Sahara. Mitochondrial DNA haplogroups L3f3 ${ }^{7}$ and L3e5, ${ }^{8}$ which are uncommon in the subSaharan area, were found to be relatively frequent in the Chad Basin region, with estimated coalescence ages similar to those we obtained for the Y chromosome R1bla haplogroup. The lineage L3f3 can be traced back over the millennia to L3f,9 and this led the researchers who analyzed L3f3 from the Chad Basin ${ }^{7}$ to propose ancient links between this haplogroup and Chadic-speaking peoples coming from East or North East Africa. However, the presence in North Africa of the supposedly autochthonous Chad Basin haplogroup L3e5,10 would seem to suggest another possible scenario, which is more compatible with the 'trans-Saharan' migration route.

Table 1 Frequencies (\%) of the $\mathrm{Y}$ chromosome $\mathrm{R} 1 \mathrm{~b} 1 \mathrm{a}$ and $\mathrm{R} 1 \mathrm{~b} 1 \mathrm{a} 4$ haplogroups in Central Africa

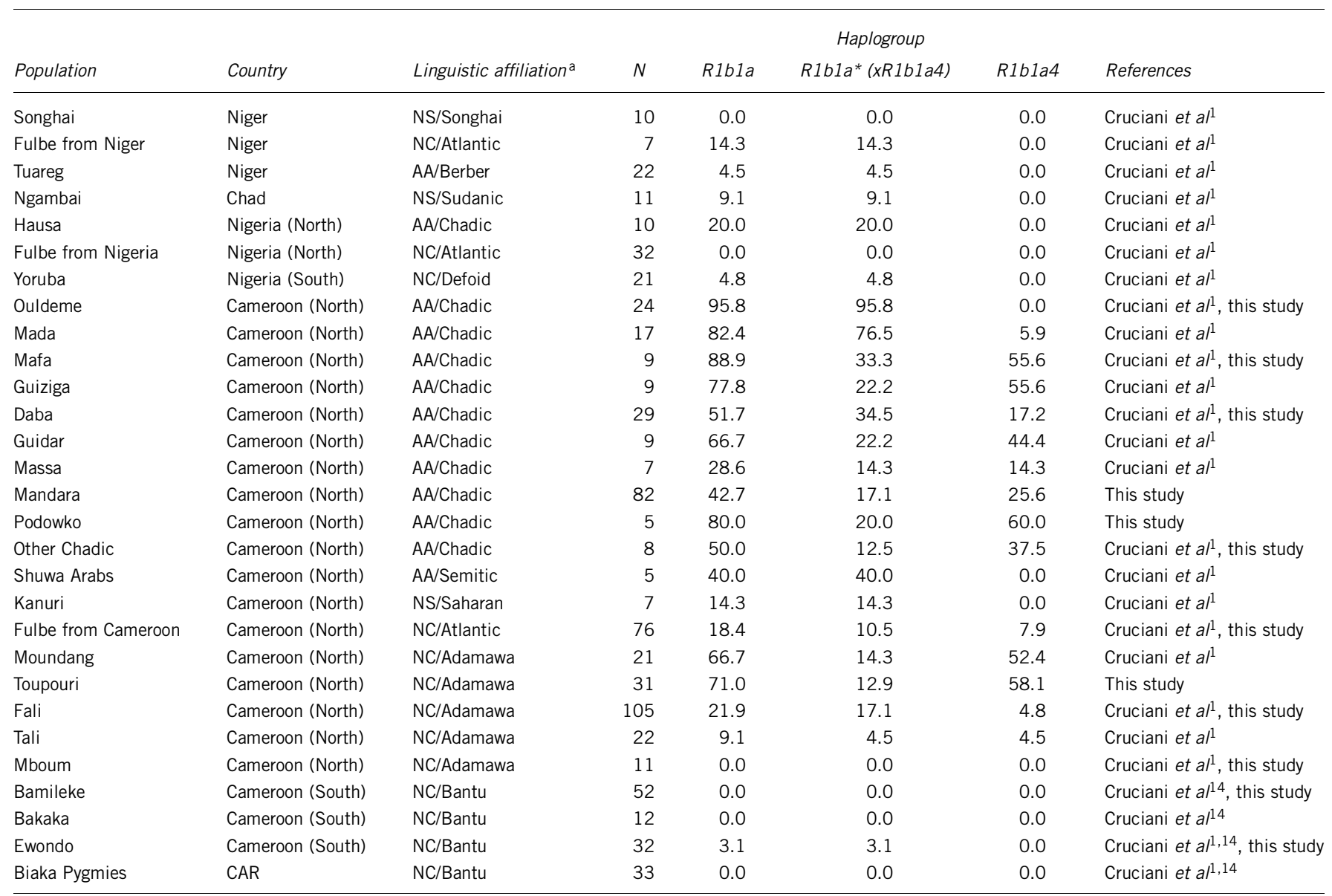

aAA, Afro-Asiatic; NC, Niger-Congo; NS, Nilo-Saharan. 
In his Letter, Lancaster ${ }^{11}$ revisits our original data and provides valuable comments on our paper. Following his own previous review, ${ }^{12}$ he argues that our interpretation may have been affected by poor population coverage in relevant regions from East and North East Africa. We agree that data from those areas that are particularly important in order to discriminate between the two theories (eg, Eastern Egypt and Sudan) would be very important. As far as we are aware, there are no data for Eastern Egypt. The investigation by Hassan et al ${ }^{13}$ in Sudan fills in the map of North East Africa, at least in part, by providing Y-chromosome haplogroup data on additional relevant population samples. However, the power of these data is limited by the low level of resolution, as no R1b1 internal markers were analyzed. Furthermore, even if one assumes that all the R1b1 Y chromosomes found in Sudan harbor the V88 mutation, there are little data to support the hypothesis that these chromosomes are the product of an ancient migration from the East. The highest frequencies of R1b1 chromosomes from Sudan were observed in the Hausa, a Chadic-speaking population that has migrated from the West, and in the Copts, a population group that is known to be largely the result of recent migrations from Egypt over the past two centuries. ${ }^{13}$ By contrast, only two R1b1 chromosomes were found among the Beja in Sudan, ${ }^{13}$ confirming our previous results that Chadic-speaking populations are distinguished from Cushites, at least at the Y chromosome variation level. ${ }^{1}$

In summary, currently available genetic evidence seems to favor our previous hypothesis ${ }^{1}$ that the $\mathrm{Y}$ chromosome haplogroup R1bla is a paternal genetic record of the proposed 'trans-Saharan' migration. ${ }^{5}$ It will be interesting to see how the proposed pattern develops as more detailed information about the phylogeographic structure of this haplogroup and a more refined method to estimate coalescence times become available.

\section{CONFLICT OF INTEREST}

The authors declare no conflict of interest.

\section{ACKNOWLEDGEMENTS}

This research received support from Grandi Progetti Ateneo, Sapienza Università di Roma, and the Italian Ministry of the University (Progetti di Ricerca di Interesse Nazionale 2007), both to RS.

Fulvio Cruciani ${ }^{1}$, Beniamino Trombetta ${ }^{1}$, Daniele Sellitto ${ }^{2}$, Andrea Massaia ${ }^{1}$, Giovanni Destro-Bisol ${ }^{3}$, Elizabeth Watson ${ }^{4}$, Eliane Beraud Colomb ${ }^{5}$, Jean-Michel Dugoujon ${ }^{6}$, Pedro Moral ${ }^{7}$ and Rosaria Scozzari ${ }^{1}$

${ }^{1}$ Dipartimento di Genetica e Biologia Molecolare, Sapienza Università di Roma, Rome, Italy;
${ }^{2}$ Istituto di Biologia e Patologia Molecolari, Consiglio Nazionale delle Ricerche, Rome, Italy; ${ }^{3}$ Dipartimento di Biologia Animale e dell'Uomo, and Istituto Italiano di Antropologia, Sapienza Università di Roma, Rome, Italy;

${ }^{4}$ The Swedish Museum of Natural History, Stockholm, Sweden; ${ }^{5}$ Laboratoire d'Immunologie, Hopital the Sainte-Marguerite, Marseille, France;

${ }^{6}$ Laboratoire d'Anthropologie Moléculaire et Imagerie de Synthèse (AMIS), Centre National de la Recherche Scientifique (CNRS) and Université de Toulouse 3, Toulouse, France;

${ }^{7}$ Departament de Biologia Animal, Universitat de Barcelona, Barcelona, Spain

E-mail: rosaria.scozzari@uniroma1.it

1 Cruciani F, Trombetta B, Sellitto D et al: Human Y chromosome haplogroup R-V88: a paternal genetic record of early mid Holocene trans-Saharan connections and the spread of Chadic languages. Eur J Hum Genet 2010; 8: 800-807.

2 Robino C, Crobu F, Di Gaetano C et al: Analysis of Y-chromosomal SNP haplogroups and STR haplotypes in an Algerian population sample. Int J Legal Med 2008; 122: 251-255.

3 Wood ET, Stover DA, Ehret $C$ et al: Contrasting patterns of $Y$ chromosome and mtDNA variation in Africa: evidence for sex-biased demographic processes. Eur J Hum Genet 2005; 13: 867-876.

4 Luis JR, Rowold DJ, Regueiro $\mathrm{M}$ et al: The Levant versus the Horn of Africa: evidence for bidirectional corridors of human migrations. Am J Hum Genet 2004; 74: 532-544.

5 Ehret C: The Civilizations of Africa: A History to 1800. Oxford: James Currey, 2002.

6 Blench R: The westward wandering of Cushitic pastoralists. Explorations in the prehistory of Central Africa; in Baroin C, Boutrais J (eds): L'Homme et l'animal dans le bassin du lac Tchad. Paris: IRD Edn, 1999, pp 39-80.

7 Černý V, Fernandes V, Costa MD, Hájek M, Mulligan CJ, Pereira L: Migration of Chadic speaking pastoralists within Africa based on population structure of Chad Basin and phylogeography of mitochondrial L3f haplogroup. BMC Evol Biol 2009; 9: 63.

8 Černý V, Salas A, Hájek M, Žaloudková M, Brdička R: A bidirectional corridor in the Sahel-Sudan belt and the distinctive features of the Chad Basin populations: a history revealed by the mitochondrial DNA genome. Ann Hum Genet 2007; 71: 433-452.

9 Salas A, Richards M, De la Fe T et al: The making of the African mtDNA landscape. Am J Hum Genet 2002; 71: 1082-1111.

10 Coudray C, Olivieri A, Achilli A et al: The complex and diversified mitochondrial gene pool of Berber populations. Ann Hum Genet 2009; 73: 196-214.

11 Lancaster A: Chadic languages and Y haplogroups. Eur J Hum Genet 2010; 18: 1187.

12 Lancaster A: Y haplogroups, archaeological cultures and language families: a review of the possibility of multidisciplinary comparisons using the case of E-M35. J Genet Geneal 2009; 5: 35-65.

13 Hassan HY, Underhill PA, Cavalli-Sforza LL, Ibrahim ME: Y-chromosome variation among Sudanese: restricted gene flow, concordance with language, geography, and history. Am J Phys Anthropol 2008; 137: 316-323.

14 Cruciani F, Santolamazza P, Shen P et al: A back migration from Asia to sub-Saharan Africa is supported by high-resolution analysis of human Y-chromosome haplotypes. Am J Hum Genet 2002; 70: 1197-1214. 